\title{
Anthropometric measures in relation to Basal Cell Carcinoma: a longitudinal study
} Catherine M Olsen*1,2, Maria Celia Hughes ${ }^{1}$, Nirmala Pandeya ${ }^{1}$ and Adèle C Green ${ }^{1,2}$

\author{
Address: ${ }^{1}$ Cancer and Population studies group, Queensland Institute of Medical Research, Brisbane, Australia and ${ }^{2}$ School of Population Health, \\ University of Queensland, Brisbane, Australia \\ Email: Catherine M Olsen* - Catherine.Olsen@qimr.edu.au; Maria Celia Hughes - Maricel.Hughes@qimr.edu.au; \\ Nirmala Pandeya - Nirmala.Pandeya@qimr.edu.au; Adèle C Green - Adele.Green@qimr.edu.au \\ * Corresponding author
}

Published: 27 March 2006

BMC Cancer 2006, 6:82 doi:10.1 |86/147|-2407-6-82
Received: 10 November 2005

Accepted: 27 March 2006

This article is available from: http://www.biomedcentral.com/147/-2407/6/82

(C) 2006 Olsen et al; licensee BioMed Central Ltd.

This is an Open Access article distributed under the terms of the Creative Commons Attribution License (http://creativecommons.org/licenses/by/2.0), which permits unrestricted use, distribution, and reproduction in any medium, provided the original work is properly cited.

\begin{abstract}
Background: The relationship between anthropometric indices and risk of basal cell carcinoma $(B C C)$ is largely unknown. We aimed to examine the association between anthropometric measures and development of $\mathrm{BCC}$ and to demonstrate whether adherence to World Health Organisation guidelines for body mass index, waist circumference, and waist/hip ratio was associated with risk of BCC, independent of sun exposure.
\end{abstract}

Methods: Study participants were participants in a community-based skin cancer prevention trial in Nambour, a town in southeast Queensland (latitude $26^{\circ} \mathrm{S}$ ). In 1992, height, weight, and waist and hip circumferences were measured for all 1621 participants and weight was remeasured at the end of the trial in 1996. Prevalence proportion ratios were calculated using a log-binomial model to estimate the risk of $B C C$ prior to or prevalent in 1992, while Poisson regression with robust error variances was used to estimate the relative risk of $B C C$ during the follow-up period.

Results: At baseline, 94 participants had a current BCC, and 202 had a history of BCC. During the 5-year follow-up period, 179 participants developed one or more new BCCs. We found no significant association between any of the anthropometric measures or indices and risk of BCC after controlling for potential confounding factors including sun exposure. There was a suggestion that short-term weight gain may increase the risk of developing BCC for women only.

Conclusion: Adherence to World Health Organisation guidelines for body mass index, waist circumference and waist/hip ratio is not significantly associated with occurrence of basal cell carcinomas of the skin.

\section{Background}

To date only two previous studies have investigated the association between anthropometric measures and basal cell carcinoma (BCC) $[1,2]$. Sahl et al (1995) in a small case-control study based on 46 cases reported a positive association between weight and BCC, whilst Milan et al (2003) in a nested case-control study of disease-discordant same-sex twin pairs based on 333 cases of BCC, found no relationship between BMI and risk of BCC. In neither 
study did the authors consider potential confounders such as phenotypic characteristics and sun exposure.

Anthropometric measures such as height, weight and body mass index (BMI) are associated with the development of certain malignancies [3]. Increasing height has been associated with increased risk of cancer of the breast, colon and prostate [3-5]. Obesity has been consistently associated with an increased risk of cancers of the colon, breast (in postmenopausal women), endometrium, kidney, oesophagus, and gastric cardia [6].

A number of hypotheses have been put forward to explain the associations of anthropometric measures and cancer. The first is that increasing height and/or weight correlate directly with the total number of cells that can undergo malignant transformation [7]. The second is that both adult height and cancer incidence are directly related to caloric intake in early life, implicating positive energy balance. Animal studies have found that reduced caloric intake during development reduces the future risk of malignancy $[8,9]$ and one study in humans also supported this hypothesis [10]. The association between height, weight and cancer may be mediated via alterations in the metabolism of endogenous hormones [11,12]. Obesity may also result in long-term storage of toxins, medications and vitamins in adipose tissue [13] or modify immune function [14].

We examined the association between anthropometric measures and indices and risk of BCC in a representative sample of people aged 25 to 75 years living in the township of Nambour, Queensland, who were followed up prospectively for a period of 4.5 years from early 1992 to late 1996. Specifically we aimed to demonstrate whether or not adherence to World Health Organisation guidelines for BMI, waist circumference and waist/hip ratio was associated with development of BCC, independent of sun exposure.

\section{Methods}

Participants were 1621 residents of Nambour, a subtropical town in South-East Queensland (latitude $26^{\circ} \mathrm{S}$ ), who were originally randomly selected from the electoral roll (enrolment is compulsory) and who were participating in the Nambour Skin Cancer Prevention Trial between 1992 and 1996 to evaluate the preventive effects of sunscreen use and/or beta-carotene supplementation. Detailed descriptions of the trial and its outcomes are reported elsewhere $[15,16]$. Participants gave written informed consent at the beginning of the trial. At baseline in 1992, height, weight, waist and hip circumference were measured. Weight was re-measured at the end of the field trial (1996). In addition, personal information was collected at interview including skin colour, eye colour, hair colour, propensity of the skin to sunburn and number of sunburns, as well as outdoor exposure during occupation and leisure (classified as mainly indoors or outdoors, or a mixture of indoors and outdoors). All anthropometric measurements were obtained by trained nurses or nutritionists using standard procedures.

Dermatologists performed full skin examinations of participants in 1992 and again in 1994 and 1996 for the majority of participants, including some who had otherwise withdrawn. In 1996, 124 people who had missed the 1994 examination were again examined by a dermatologist. Every participant had at least one follow-up examination with a dermatologist in either 1994 or 1996. All lesions clinically diagnosed as BCC were biopsied for histologic confirmation by a single dermatopathologist. In addition, participants were followed-up every 3 months and any new cancers treated by the participant's General Practitioner were documented and later validated against histological records. Finally and with participants' consent, independent pathology laboratories throughout Queensland provided reports on all skin cancers diagnosed during the entire trial period for cross-checking. History of BCC or squamous cell carcinoma (SCC) prior to 1986 was obtained from a prevalence survey of skin cancer and actinic skin damage conducted in December 1986 [17], and BCCs and SCCs treated between 1986 and 1992 were monitored via surveys conducted between 1986 and $1992[18,19]$.

The study was approved by the Queensland Institute of Medical Research ethics committee and abided by the Declaration of Helsinki on research on human subjects.

\section{Data analysis}

Weight and height were expressed as quartiles of the distribution for the entire at-risk cohort, while BMI, waist circumference and waist/hip ratios were classified using World Health Organisation (WHO) definitions of obesity. The WHO BMI classification for adults was based on results of studies that linked morbidity and mortality to body weight [20] (<18.5 "underweight"; 18.5-24.9 "normal weight"; 25-29.9 "overweight"; and $\geq 30$ obese). Waist circumference was categorised using the sex-specific WHO cut-offs for risk of metabolic complications in Caucasians [21]. Waist circumference measurements of $<94$ $\mathrm{cm}$ for males and $<80 \mathrm{~cm}$ for females were classified as 'desirable'; $94-102 \mathrm{~cm}$ for males and $80-88 \mathrm{~cm}$ for females were classified as 'increased obesity-associated risk'; and $>102 \mathrm{~cm}$ for males and $>88 \mathrm{~cm}$ for females were classified as 'substantially increased obesity-associated risk'. Waist/hip ratio was divided into two sex-specific categories, since high ratios $(>1.0$ in men and $>0.85$ in women) is taken to indicate abdominal fat accumulation [22]. 
Two outcomes were examined: presence of one or more BCCs prior to the baseline survey or prevalent at the baseline survey in 1992 ('prevalent' BCC); and incidence of one or more histologically confirmed BCCs between the baseline survey in 1992 and 1996 ('incident' BCC).

Prevalence proportion ratios (PPR) with 95\% confidence intervals (95\% CI) were calculated as estimates of the risk of prevalent BCC associated with weight quartiles, height quartiles, BMI category, waist circumference and waist/ hip ratio category, using the lowest category of each as the reference category. A multiplicative generalized linear model with logarithmic link function and binomial distribution function [23] was used to adjust for age and potential confounders such as education, smoking status, skin colour, hair colour, skin type, occupation type, leisure type, number of painful sunburns in lifetime, and use of hormone replacement therapy. Only those factors that changed the point estimate by $>10 \%$ were included in the final models. Occupational exposure was taken to indicate cumulative sun exposure and leisure-time exposure, as indicating an irregular sun exposure pattern. Height was assessed as a potential confounder in the analyses for weight, waist circumference and waist/hip ratio categories, but it did not change the point estimate by $>10 \%$ and so was not included in the final models.

To assess anthropometric measures at baseline in relation to incidence of BCC 1992-1996, relative risks (RR) for the binary outcome (new BCC 1992-1996 or no BCC ever) associated with weight quartiles, height quartiles, BMI, waist circumference and waist/hip ratio categories at baseline were calculated using a Poisson regression with robust error variance [24]. Multivariate Poisson regression was used to adjust for age and history of BCC, and other potential confounders as described for the analyses of prevalent BCC. Effect modification for both outcomes (prevalent and incident BCC) was assessed by comparing stratum-specific point estimates. If the stratum-specific point estimates appeared to differ, multiplicative terms were entered in to the model. A p-value of $<0.05$ for the multiplicative term was interpreted as significant effect modification. We also tested for homogeneity of the stratum-specific point estimate using chi-square test for homogeneity [25].

Possible relationship between change in weight 19921996 and incidence of BCC 1992-1996 was also investigated. Four arbitrary groups were created to describe weight change over the period 1992-1996: $\leq-4 \mathrm{~kg},-4 \mathrm{~kg}$ to $<4 \mathrm{~kg}, 4 \mathrm{~kg}$ to $10 \mathrm{~kg}$, and $>10 \mathrm{~kg}$. The reference category for weight change was $-4 \mathrm{~kg}$ to $4 \mathrm{~kg}$. Relative risks (RR) with 95\% confidence intervals were calculated using multivariate Poisson regression, adjusting for age, history of BCC, weight at baseline, hair colour and eye colour. To take into account the participants who had withdrawn without complete skin examination by a dermatologist in the follow-up period, total person-years were calculated for each participant, and the log-transformation of this variable was used as an off-set variable in the model.

Analyses were conducted using SAS (SAS Institute, Cary, North Carolina, USA).

\section{Results}

Of the 1621 people (710 male and 911 female) who enrolled in the field trial at baseline, 238 participants (15\%) withdrew without complete skin examination by a dermatologist in the follow-up period. Those with withdrew without follow-up examination were younger on average than the remaining participants (mean 47.0 vs 49.1 years), but were similar in all other respects [16]. In 1992 weight was recorded for 1233 participants, and height for 1112; both weight and height measurements were available for 1109 participants. Waist circumference and hip circumference was measured for 1221 participants, waist-hip ratio able to be calculated for 1220 participants. Weight in 1996 was recorded for 1271 participants; weight change 1992-1996 was available for 1079 participants.

Of this population sample, 55\% had fair skin, 38\% medium skin and only $7 \%$ olive or brown skin ( $\mathrm{p}<$ $0.001)$. Most (68\%) participants had a skin type that burned then tanned after acute sun exposure [26]. A high proportion of the sample (44\%) reported that their main occupation was indoors, but in terms of leisure activities, only $15 \%$ of the sample reported that their main leisure activity was indoors.

Mean age at baseline was 50.7 years for men and 49.6 for women. At baseline 94 participants $(6 \%)$ had a current BCC; 212 (13\%) had been diagnosed with BCC in the past; and 82 participants ( $5 \%$ ) had both a prevalent and a past history of BCC. During the follow-up period, 179 participants (12\%) developed one or more new BCCs (97 (54\%) of whom had no previous history of BCC). Of the women study participants, $1 \%$ were underweight $(\mathrm{BMI}<18.5), 32 \%$ were overweight (BMI 25-29.9), and $17 \%$ were obese $(\mathrm{BMI} \geq 30)$. Few males $(0.4 \%)$ were underweight, but $48 \%$ were overweight and a further $16 \%$ were obese.

Adjusted PPRs of prevalent BCC associated with anthropometric measures are shown in Table 1. For BMI the reference category was $<25$ (underweight and normal categories combined) as there were only 8 individuals in the underweight category. There was no association between prevalence of BCC and height for women or men; the PPR estimates for height were elevated only for 
Table I: Height, weight, BMI, waist circumference, waist/hip ratio and risk of BCC at baseline (1992)

\begin{tabular}{|c|c|c|c|c|c|c|c|c|c|c|}
\hline & \multicolumn{5}{|c|}{ Males } & \multicolumn{5}{|c|}{ Females } \\
\hline & $\mathrm{BCC}$ & & No $B C C$ & & $\operatorname{PPR}(95 \% \mathrm{Cl})^{\mathrm{a}}$ & $\mathrm{BCC}$ & & No BCC & & $\operatorname{PPR}(95 \% \mathrm{Cl})^{\text {a }}$ \\
\hline & $\mathrm{N}$ & $\%$ & $\mathrm{~N}$ & $\%$ & & $\mathrm{~N}$ & $\%$ & $\mathrm{~N}$ & $\%$ & \\
\hline \multicolumn{11}{|l|}{$\begin{array}{l}\text { Weight } \\
\text { quartile }\end{array}$} \\
\hline QI & 22 & 25 & 109 & 25 & 1.0 & 20 & 25 & 152 & 25 & 1.0 \\
\hline Q2 & 22 & 25 & 112 & 25 & I.2(0.7-2.0) & 21 & 26 & 157 & 25 & $0.9(0.5-1.6)$ \\
\hline Q3 & 26 & 30 & 108 & 24 & $1.4(0.8-2.2)$ & 13 & 16 & 162 & 26 & $0.6(0.3-I . I)$ \\
\hline Q4 & 17 & 20 & 116 & 26 & $0.9(0.5-1.0)$ & 26 & 33 & 150 & 24 & I.I (0.7-I.9) \\
\hline$n=1223$ & & & & & $p=0.45$ & & & & & $p=0.14$ \\
\hline \multicolumn{11}{|l|}{$\begin{array}{l}\text { Height } \\
\text { quartile }\end{array}$} \\
\hline QI & 27 & 34 & 90 & 22 & 1.0 & 21 & 29 & 136 & 24 & 1.0 \\
\hline Q2 & 13 & 17 & 100 & 25 & $0.6(0.3-1.1)$ & 19 & 26 & 140 & 25 & I.0 (0.6-I.8) \\
\hline Q3 & 18 & 23 & 111 & 28 & $0.8(0.5-1.3)$ & 12 & 16 & 144 & 26 & $0.8(0.4-1.5)$ \\
\hline Q4 & 21 & 27 & 100 & 25 & I.3 (0.8-2.I) & 21 & 29 & 139 & 25 & $1.4(0.8-2.5)$ \\
\hline $\mathrm{n}=1112$ & & & & & $p=0.07$ & & & & & $p=0.31$ \\
\hline \multicolumn{11}{|l|}{$\begin{array}{l}\text { BMI } \\
\text { category } \\
\left(\mathrm{kg} / \mathrm{m}^{2}\right)\end{array}$} \\
\hline$<25$ & 30 & 38 & 142 & 36 & 1.0 & 33 & 45 & 286 & 51 & 1.0 \\
\hline $25-29.9$ & 38 & 48 & 192 & 48 & I.0 (0.6-I.4) & 23 & 32 & 179 & 32 & $0.9(0.6-1.5)$ \\
\hline$\geq 30$ & 11 & 14 & 66 & 17 & $0.8(0.4-1.5)$ & 17 & 23 & 92 & 17 & $1.2(0.7-2.1)$ \\
\hline$n=1109$ & & & & & $p=0.76$ & & & & & $p=0.64$ \\
\hline \multicolumn{11}{|l|}{$\begin{array}{l}\text { Waist } \\
\text { category } \\
(\mathrm{cm})\end{array}$} \\
\hline $\begin{array}{l}<94(\mathrm{M}) \\
<80(\mathrm{~F})\end{array}$ & 31 & 36 & 197 & 45 & 1.0 & 31 & 39 & 271 & 44 & 1.0 \\
\hline $\begin{array}{l}94-101.9 \\
(\mathrm{M}) ; 80- \\
87.9(\mathrm{~F})\end{array}$ & 30 & 35 & 114 & 26 & I.3 (0.9-2.0) & 49 & 61 & 343 & 43 & $0.9(0.6-1.5)$ \\
\hline $\begin{array}{l}102+(M) \\
88+(F)\end{array}$ & 26 & 30 & 129 & 29 & $1.0(0.6-1.5)$ & 0 & & 0 & & \\
\hline$n=1221$ & & & & & $p=0.31$ & & & & & $p=0.79$ \\
\hline \multicolumn{11}{|l|}{$\begin{array}{l}\text { Waist/hip } \\
\text { ratio } \\
\text { category }\end{array}$} \\
\hline $\begin{array}{l}\geq 1.0(\mathrm{M}) \\
\geq 0.85(\mathrm{~F})\end{array}$ & 78 & 90 & 397 & 90 & 1.0 & 64 & 80 & 526 & 88 & 1.0 \\
\hline 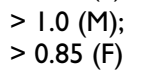 & 9 & 10 & 43 & 10 & $0.8(0.4-1.4)$ & 16 & 20 & 87 & 12 & $1.0(0.6-1.7)$ \\
\hline$n=1220$ & & & & & $p=0.4 I$ & & & & & $p=0.90$ \\
\hline
\end{tabular}

a Adjusted for age; waist/hip ratio category adjusted for age and skin colour

the tallest people, but not significantly. Also no significant associations were seen between prevalence of BCC and weight, waist/hip ratio or waist circumference.

Similarly, anthropometric measures were unrelated to development of new BCCs. Women in the highest quartile of weight had a small increased risk (RR 1.4, 95\% CI 0.92.4), but this was not statistically significant (Table 2). A separate analysis of incident BCC was performed for par- ticipants without a history of BCC, however the results did not differ significantly from those presented.

With respect to short-term weight change and development of BCC 1992-1996, weight gain showed a suggestive positive association with BCC for women (Table 2), but the point estimates were not statistically significant. Compared with women who gained or lost up to $4 \mathrm{~kg}$, the risk of developing a BCC during the follow-up period was 
higher in those who gained 4-10 kg (RR 1.4, 95\% CI 0.82.5 ), and in those who gained $10 \mathrm{~kg}$ or more (RR $1.7,95 \%$ CI 0.5-5.6). For men, the RRs were only slightly elevated for those who gained $4-10 \mathrm{~kg}$, and again this association was not statistically significant.

\section{Discussion}

The relationship between anthropometric indices and occurrence of BCC has been little studied. To our knowledge, only two studies have investigated BCC in relation to anthropometric measures or indices $[1,2]$. The study by Milan et al. (2003) did not measure important potential confounders including phenotypic characteristics or sun exposure history, and although information on these potential confounders was collected in the study by Sahl et al. (1995), they did not consider them in their analyses which was limited to comparing the mean body weight of a small number of cases and controls (49 and 46 respectively). Although the current study was also not designed specifically to examine the association between anthropometric measures and BCC, information on a large number of other risk factors, including phenotypic characteristics and sun exposure history, was collected and these risk factors were assessed as possible confounders in the relationship between BCC and anthropometric measures.

In the present large prospective study, there were no significant associations between any of the anthropometric measures or indices and BCC, though a suggestive positive association between short term weight gain and development of BCC in women was observed. This implies that a stable body weight may be more favourable with respect to the development of BCC then short-term changes in body weight in this study population. It is unclear why weight gain might be associated with the development of BCC. Weight gain is a consequence of higher energy intake than energy expenditure over time, and availability or restriction of energy can modulate the cellular replication process. There is evidence from studies of different animal models that suggests caloric restriction inhibits cell proliferation [27] and carcinogenesis [28,29]. One study in human subjects also supported this hypothesis [10]. These data have been further supported by recent epidemiological studies that demonstrate the importance of energy balance and obesity in human cancer $[3,5,30$ 32].

The association between weight gain and BCC, if confirmed by other studies, may be mediated via alterations in the metabolism of endogenous hormones (sex steroids, insulin and insulin-like growth factors) (that lead to a change in the normal balance between cell proliferation, differentiation and apoptosis $[11,12,33])$, or through reduction in immunity [14], although this hypothesis is based on results of animal studies.
For weight and BMI at baseline, no association was observed. Some research has suggested that adult weight gain may be a better variable to assess adiposity and its metabolic consequences than body weight itself [33], since weight gain largely reflects an increase in body fat, whereas weight reflects both lean and fat body mass. Height seemed to be associated inconsistently with an increased risk of developing BCC, but the point estimates were not significant, and there were no significant tests for trend. Tallness has been associated with increased risk of a number of other cancers, including cancers of the breast, colon, and prostate [3-5] and the same biological mechanisms as described above for weight gain have been proposed to explain these associations. It may also be possible that there is some behavioural correlate of body height related to sun exposure, such as participation in outdoor sporting activities [34], that increases the likelihood of developing BCC.

Strengths of this study include its large population sample with a high participation rate as well as its prospective design, and the ability to assess a large number of other risk factors as possible confounders of the association between anthropometric measures and BCC. Standardised methods for measuring weight and height, and comprehensive data on BCC incidence from 1992 -1996 were also features of this investigation. Our large prospective study did not have the limitations of the previous two studies. The case-control study by Sahl et al. (1995) was based on a very small number of clinic-based cases of BCC (less than 50), and thus it was limited in power, susceptible to selection bias due to non-representative cases and controls and to faulty recall of past weight and height measurements. Indeed both previous studies relied upon self-reported weight and height measurements. In the second study by Milan et al. (2003), subjects were drawn from a twin cohort and a single self-reported weight was the basis of their assessment of BMI in relation to incident BCC over the next 23 years. That is, no account of weight change or assessment of latent effect of BMI on disease was possible. Our study reported here was a prospective, population-based study of anthropometric measures and BCC and thus susceptible to neither recall nor selection biases. It is the first study to have used objectively measured height and weight, together with measured waist and hip circumference in relation to BCC, and the only study to have examined weight change. Also the potential influences of most known risk factors for BCC were thoroughly assessed.

Limitations of the study include reliance on self-report of BCC prior to 1986, and availability of only a single height measurement in 1992. In older adults (age 60+), height can decrease with age due to spinal deformity and thinning of the intervertebral discs [35]. This decrease in 
Table 2: Height, weight, BMI, waist circumference, waist/hip ratio and weight change and incidence of BCC 1992-I996

\begin{tabular}{|c|c|c|c|c|c|c|c|c|c|c|}
\hline & \multicolumn{5}{|c|}{ Males } & \multicolumn{5}{|c|}{ Females } \\
\hline & $\mathrm{BCC}$ & & $\begin{array}{c}\text { No } \\
\text { BCC }\end{array}$ & & $\operatorname{RR}(95 \% \mathrm{Cl})^{a}$ & $\mathrm{BCC}$ & & $\begin{array}{c}\text { No } \\
\text { BCC }\end{array}$ & & $\operatorname{RR}(95 \% \mathrm{Cl})^{a}$ \\
\hline & $\mathrm{N}$ & $\%$ & $N$ & $\%$ & & $N$ & $\%$ & $\mathrm{~N}$ & $\%$ & \\
\hline \multicolumn{11}{|l|}{ Weight quartile } \\
\hline QI & 23 & 30 & 97 & 24 & 1.0 & 17 & 21 & $|4|$ & 25 & 1.0 \\
\hline Q2 & 15 & 20 & 107 & 26 & $0.7(0.5-1.1)$ & 19 & 24 & 146 & 26 & I.I (0.6-I.8) \\
\hline Q3 & 21 & 28 & 100 & 24 & $0.9(0.6-1.3)$ & 17 & 21 & 152 & 27 & $0.9(0.5-1.5)$ \\
\hline Q4 & 17 & 22 & 106 & 26 & $1.0(0.6-1.5)$ & 27 & 34 & $|3|$ & 23 & $1.4(0.9-2.4)$ \\
\hline$n=1223$ & & & & & $p=0.29$ & & & & & $p=0.22$ \\
\hline \multicolumn{11}{|l|}{ Height quartile } \\
\hline QI & 18 & 27 & 84 & 23 & 1.0 & 19 & 25 & 125 & 24 & 1.0 \\
\hline Q2 & 15 & 23 & 92 & 25 & $1.3(0.8-2.1)$ & 20 & 27 & 127 & 25 & $1.0(0.6-1.6)$ \\
\hline Q3 & 21 & 32 & 98 & 26 & $1.5(1.0-2.3)$ & 16 & 21 & 133 & 26 & $1.0(0.6-1.7)$ \\
\hline Q4 & 12 & 18 & 97 & 26 & $0.9(0.6-1.4)$ & 20 & 27 & 127 & 25 & I.3 $(0.8-2.3)$ \\
\hline $\mathrm{n}=1112$ & & & & & $p=0.16$ & & & & & $p=0.62$ \\
\hline \multicolumn{11}{|l|}{ BMI category $\left(\mathrm{kg} / \mathrm{m}^{2}\right)$} \\
\hline$<25$ & 23 & 35 & $|3|$ & 35 & 1.0 & 35 & 47 & 262 & 51 & 1.0 \\
\hline $25-29.9$ & 34 & 52 & 178 & 48 & $0.9(0.6-1.4)$ & 26 & 35 & 166 & 33 & $0.7(0.5-1.1)$ \\
\hline$\geqslant 30$ & 9 & 14 & 61 & 17 & $1.0(0.6-1.7)$ & 14 & 19 & 82 & 16 & $1.2(0.7-2.0)$ \\
\hline $\mathrm{n}=1109$ & & & & & $p=0.94$ & & & & & $p=0.15$ \\
\hline \multicolumn{11}{|l|}{ Waist category $(\mathrm{cm})$} \\
\hline$<94(\mathrm{M}) ;<80(\mathrm{~F})$ & 27 & 36 & 182 & 45 & 1.0 & 26 & 33 & 252 & 45 & 1.0 \\
\hline $94-101.9(\mathrm{M}) ; 80-87.9(\mathrm{~F})$ & 25 & 33 & 106 & 26 & $0.9(0.6-1.3)$ & 53 & 67 & 312 & 55 & $1.0(0.8-1.4)$ \\
\hline $102+(M) ; 88+(F)$ & 24 & 32 & 117 & 29 & $1.0(0.6-1.5)$ & 0 & & 0 & & \\
\hline$n=1221$ & & & & & $p=0.83$ & & & & & $p=0.71$ \\
\hline \multicolumn{11}{|l|}{ Waist/hip ratio category } \\
\hline$\geqslant 1.0(\mathrm{M}) ; \geqslant 0.85(\mathrm{~F})$ & 69 & 91 & 365 & 90 & 1.0 & 63 & 80 & 485 & 86 & 1.0 \\
\hline$>1.0(\mathrm{M}) ;>0.85(\mathrm{~F})$ & 7 & 9 & 40 & 10 & $0.9(0.5-1.5)$ & 16 & 20 & 78 & 14 & I.I (0.7-I.7) \\
\hline$n=1220$ & & & & & $p=0.53$ & & & & & $p=0.85$ \\
\hline \multicolumn{11}{|l|}{ Weight change (kg) } \\
\hline$<-4$ & 10 & 14 & 29 & 18 & $1.2(0.6-2.5)$ & 14 & 19 & 44 & 9 & $1.5(0.8-2.7)$ \\
\hline$-4-3.9$ & 48 & 66 & 232 & 65 & 1.0 & 37 & 51 & 311 & 62 & 1.0 \\
\hline $4-10$ & 15 & 21 & 85 & 24 & I.I (0.6-1.9) & 18 & 25 & 115 & 23 & $1.4(0.8-2.5)$ \\
\hline $10+$ & 0 & 0 & 13 & 4 & & 4 & 6 & 29 & 6 & $1.7(0.5-5.6)$ \\
\hline$n=1004$ & & & & & $p=0.63$ & & & & & $p=0.52$ \\
\hline
\end{tabular}

a Adjusted for age, and history of BCC

Weight quartile and waist circumference category adjusted for age, history of $\mathrm{BCC}$ and hair colour

Height quartile and BMI category adjusted for age, history of BCC and eye colour

Weight change category adjusted for age, history of BCC, weight at baseline, hair and eye colour

height has been reported to range from $0.5-1.5 \mathrm{~cm} / \mathrm{dec}$ ade [35], to $2.5-5 \mathrm{~cm} /$ decade [36]. We could therefore expect that there would have been some change in height for the $26.9 \%$ of study participants aged over 60 years (in 1992), however we would expect this change in height to be modest over the 4.5 year follow-up period.

\section{Conclusion}

Adherence to WHO guidelines for BMI, waist circumference, waist/hip ratio appears not to be associated with occurrence of BCC, though there may be a positive associ- ation between weight gain and occurrence of BCC in women that warrants further investigation.

\section{Competing interests}

The author(s) declare that they have no competing interests.

\section{Authors' contributions}

$\mathrm{CO}$ performed the statistical analysis, and drafted the manuscript. AG participated in the design and coordination of the study. CO, AG and MH were involved in criti- 
cally revising the manuscript. NP advised on statistical analysis and interpretation of the data. All authors read and approved the final manuscript.

\section{Acknowledgements}

We thank the participants from the Nambour community for their longstanding dedication and commitment. This study was supported by the National Health and Medical Research Council of Australia. Maria Celia Hughes was funded by the World Cancer Research Fund International.

\section{References}

I. Sahl WJ, Glore S, Garrison P, Oakleaf K, Johnson SD: Basal cell carcinoma and lifestyle characteristics. Int J Dermatol 1995 , 34(6):398-402.

2. Milan T, Verkasalo PK, Kaprio J, Koskenvuo M: Lifestyle differences in twin pairs discordant for basal cell carcinoma of the skin. Br J Dermatol 2003, I 49(I): I I5-I23.

3. Calle EE, Rodriguez C, Walker-Thurmond K, Thun MJ: Overweight, obesity, and mortality from cancer in a prospectively studied cohort of U.S. adults. N Engl J Med 2003, 348(17):1625-1638.

4. Hebert PR, Ajani U, Cook NR, Lee IM, Chan KS, Hennekens CH: Adult height and incidence of cancer in male physicians (United States). Cancer Causes Control 1997, 8(4):591-597.

5. Albanes D, Jones DY, Schatzkin A, Micozzi MS, Taylor PR: Adult stature and risk of cancer. Cancer Res 1988, 48(6): 1658-I662.

6. Bianchini F, Kaaks R, Vainio H: Overweight, obesity, and cancer risk. Lancet Oncol 2002, 3(9):565-574.

7. Albanes D, Winick M: Are cell number and cell proliferation risk factors for cancer? I Nat Cancer Inst 1988, 80(10):772-774.

8. Ross $\mathrm{MH}$, Bras $\mathrm{G}$ : Tumor incidence patterns and nutrition in the rat. J Nutr 1965, 87(3):245-260.

9. Ross $\mathrm{MH}$, Bras $\mathrm{G}$ : Lasting influence of early caloric restriction on prevalence of neoplasms in the rat. J Natl Cancer Inst I97I, 47(5): 1095-III3.

10. Frankel S, Gunnell DJ, Peters TJ, Maynard M, Davey Smith G: Childhood energy intake and adult mortality from cancer: the Boyd Orr Cohort Study. Bmj 1998, 3 I 6(7 I 30):499-504.

II. Juul A, Dalgaard P, Blum WF, Bang P, Hall K, Michaelsen KF, Muller J, Skakkebaek NE: Serum levels of insulin-like growth factor (IGF)-binding protein-3 (IGFBP-3) in healthy infants, children, and adolescents: the relation to IGF-I, IGF-II, IGFBP-I, IGFBP-2, age, sex, body mass index, and pubertal maturation. J Clin Endocrinol Metab 1995, 80(8):2534-2542.

12. Henderson BE, Ross RK, Pike MC, Casagrande JT: Endogenous hormones as a major factor in human cancer. Cancer Res 1982 42(8):3232-3239.

13. Krotkiewski M, Bjorntorp P, Sjostrom L, Smith U: Impact of obesity on metabolism in men and women. Importance of regional adipose tissue distribution. | Clin Invest |983, 72(3): | | 50- | | 62.

14. Scrimshaw NS, SanGiovanni JP: Synergism of nutrition, infection, and immunity: an overview. Am \& Clin Nutr 1997, 66(2):464S-477S

15. Green A, Battistutta D, Hart V, Leslie D, Marks G, Williams G, Gaffney P, Parsons P, Hirst L, Frost C, et al.: The Nambour Skin Cancer and Actinic Eye Disease Prevention Trial: design and baseline characteristics of participants. Control Clin Trials 1994, I 5(6):512-522.

16. Green A, Williams G, Neale R, Hart V, Leslie D, Parsons P, Marks GC, Gaffney $P$, Battistutta $D$, Frost $C$, Lang $C$, Russell $A$ : Daily sunscreen application and betacarotene supplementation in prevention of basal-cell and squamous-cell carcinomas of the skin: a randomised controlled trial. Lancet 1999, 354(9 | 80):723-729.

17. Green A, Beardmore G, Hart V, Leslie D, Marks R, Staines D: Skin cancer in a Queensland population. J Am Acad Dermatol 1988, 1 9(6): 1045-1052

18. Green A, Battistutta $D$ : Incidence and determinants of skin cancer in a high-risk Australian population. Int J Cancer 1990 46(3):356-36I.

19. Green A, Battistutta D, Hart V, Leslie D, Weedon D: Skin cancer in a subtropical Australian population: incidence and lack of association with occupation. The Nambour Study Group. Am J Epidemiol 1996, I 44(I I): 1034-1040.
20. Physical status: the use and interpretation of anthropometry. Report of a WHO Expert Committee. World Health Organ Tech Rep Ser 1995, 854: I-452.

21. Obesity: preventing and managing the global epidemic. Report of a WHO consultation. World Health Organ Tech Rep Ser 2000, 894:i-xii, I-253.

22. Han TS, Seidell JC, Currall JE, Morrison CE, Deurenberg P, Lean ME: The influences of height and age on waist circumference as an index of adiposity in adults. Int J Obes Relat Metab Disord 1997. 2I(I):83-89.

23. Skov T, Deddens J, Petersen MR, Endahl L: Prevalence proportion ratios: estimation and hypothesis testing. Int J Epidemiol 1998, 27(I):9|-95

24. Zou G: A modified poisson regression approach to prospective studies with binary data. Am J Epidemiol 2004, I59(7):702-706.

25. Greenland S, Rothman KJ: Introduction to stratified analysis. In Modern Epidemiology Edited by: Rothman KJ, Greenland S. Philadelphia , Lippincott-Raven; 1998:253-28I.

26. Valery PC, Neale R, Williams G, Pandeya N, Siller G, Green A: The effect of skin examination surveys on the incidence of basal cell carcinoma in a Queensland community sample: a 10year longitudinal study. J Investig Dermatol Symp Proc 2004, 9(2): $|48-| 5 \mid$

27. Turturro A, Blank K, Murasko D, Hart R: Mechanisms of caloric restriction affecting aging and disease. Ann N Y Acad Sci 1994 719:159-170

28. Birt DF, Pelling JC, White LT, Dimitroff K, Barnett T: Influence of diet and calorie restriction on the initiation and promotion of skin carcinogenesis in the SENCAR mouse model. Cancer Res 199|, 5 I(7): 1851-1854.

29. Birt DF, Przybyszewski J, Wang W, Stewart J, Liu Y: Identification of molecular targets for dietary energy restriction prevention of skin carcinogenesis: an idea cultivated by Edward Bresnick. J Cell Biochem 2004, 9 I (2):258-264.

30. Patel AV, Rodriguez C, Bernstein L, Chao A, Thun MJ, Calle EE: Obesity, recreational physical activity, and risk of pancreatic cancer in a large u.s. Cohort. Cancer Epidemiol Biomarkers Prev 2005, I 4(2):459-466.

31. Ross JA, Parker E, Blair CK, Cerhan JR, Folsom AR: Body mass index and risk of leukemia in older women. Cancer Epidemiol Biomarkers Prev 2004, I3( I I Pt I): |810-1813.

32. Murphy TK, Calle EE, Rodriguez C, Kahn HS, Thun MJ: Body mass index and colon cancer mortality in a large prospective study. Am J Epidemiol 2000, 152(9):847-854.

33. McCullough ML, Giovannucci EL: Diet and cancer prevention. Oncogene 2004, 23(38):6349-6364.

34. Norton K, Olds T: Morphological evolution of athletes over the 20th century: causes and consequences. Sports Med 200I, 3 I (II):763-783.

35. Baumgartner RN, Stauber PM, McHugh D, Koehler KM, Garry PJ: Cross-sectional age differences in body composition in persons 60+ years of age. I Gerontol A Biol Sci Med Sci 1995, 50(6):M307-I6.

36. de Groot CP, Perdigao AL, Deurenberg P: Longitudinal changes in anthropometric characteristics of elderly Europeans. SENECA Investigators. Eur J Clin Nutr 1996, 50 Suppl 2:S9-15.

\section{Pre-publication history}

The pre-publication history for this paper can be accessed here:

http://www.biomedcentral.com/1471-2407/6/82/prepub 